\title{
Key promoter elements involved in transcriptional activation of the cancer-related gene coding for $\mathrm{S100P}$ calcium-binding protein
}

\author{
ADRIANA GIBADULINOVA ${ }^{1}$, INGRID OVECKOVA ${ }^{1}$, SEPPO PARKKILA ${ }^{2}$, \\ SILVIA PASTOREKOVA ${ }^{1}$ and JAROMIR PASTOREK ${ }^{1}$ \\ ${ }^{1}$ Centre of Molecular Medicine, Institute of Virology, Slovak Academy of Sciences, Dubravska cesta 9, \\ 84505 Bratislava, Slovakia; ${ }^{2}$ Institute of Medical Technology and School of Medicine, \\ Tampere University and University Hospital, Tampere, Finland
}

Received March 21, 2008; Accepted May 9, 2008

DOI: $10.3892 /$ or_00000020

\begin{abstract}
S100P gene encodes a calcium-binding protein expressed in different tumor tissues and is functionally implicated in malignant phenotype. Despite consistent relationship to cancer, regulation of S100P gene expression has remained unexplored. Here we determined the transcription start and defined the S100P core promoter. Using a series of the promoter constructs analyzed by dual luciferase reporter assay, we identified SMAD, STAT/CREB and $\mathrm{SP} / \mathrm{KLF}$ binding sites as critical cis-elements required for S100P expression in cancer cells. We also demonstrated in EMSA that these elements bind nuclear factors, and showed their functional significance by promoter deletion analysis. This study represents the first coherent contribution to understanding of factors and pathways responsible for S100P gene activation in cancer.
\end{abstract}

\section{Introduction}

S100 proteins, belonging to a family of EF-hand calciumbinding proteins, act as intracellular and/or extracellular signaling molecules with regulatory functions in diverse cellular processes such as differentiation, proliferation and malignant transformation. Expression of S100 proteins has been associated with several human diseases including cardiomyopathy, diabetes, neurodegenerative disorders and cancer (1). S100P protein, originally isolated from placenta, is a small $11-\mathrm{kDa}$ protein consisting of 95 amino acids $(2,3)$. It forms calcium-dependent homodimers $(4,5)$ and interacts with a cytoskeletal protein ezrin, which plays a role in cell

Correspondence to: Professor Jaromir Pastorek, Institute of Virology, Slovak Academy of Sciences, Dubravska cesta 9, 84505 Bratislava, Slovak Republic

E-mail: virupast@savba.sk

Key words: $\mathrm{S} 100 \mathrm{P}$ calcium-binding protein, transcription initiation, promoter, luciferase assay, electromobility shift assay, cancer adhesion and motility (6). S100P also binds to a CacyBP/SIP component of the ubiquitin pathway involved in degradation of the cell adhesion molecule B-catenin (7). Moreover, S100P exists in a soluble form and functions as an extracellular RAGE receptor ligand modulating cell proliferation and survival via activation of MAP kinase pathway (8).

Based on molecular investigations, tissue expression studies and microarray analyses, S100P has been implicated in tumor development. Expression of S100P was detected in tumor cell lines and carcinomas derived from the breast, pancreas, prostate, colon, and other tumor types, and was associated with immortalized, malignant, hormoneindependent and chemoresistant phenotype (9-17). However, only few reports describe regulation of S100P expression. In the prostate carcinoma cell lines and tissues, expression of S100P is controlled by androgens (18) and depends on hypomethylation of S100P gene $(19,20)$. In the gastric cancer cells, S100P biosynthesis is induced by retinoic acid (21).

Despite increasing number of studies showing biological significance of S100P protein and its relationship to cancer, no promoter analysis of S100P gene has been published so far and data on its transcriptional control are missing. This fact motivated us to perform the present investigation and define critical regulatory elements involved in activation of S100P transcription.

\section{Materials and methods}

Cell culture. HeLa, SiHa and C33A cervical carcinoma cells, MFC-7 and BT-20 breast carcinoma cells were cultured under standard conditions in DMEM supplemented with $10 \%$ FCS, L-glutamine and 100 units/ml penicillin/streptomycin mixture (all from BioWhittaker, Verviers, Belgium) in humidified air containing $5 \% \mathrm{CO}_{2}$ at $37^{\circ} \mathrm{C}$.

5'-RACE mapping of transcription start site. Rapid amplification of the 5' S100P cDNA ends was performed using RACE kit (Invitrogen, Carlsbad, USA) according to the manufacturer's recommendations, using the gene-specific primers GSP1 S100P-A and GSP2 S100P-A (Table I) combined with the abridged anchor primers supplied with the kit. cDNA template was produced by reverse transcription 
Table I. Primers and oligonucleotides used in the RACE, PCR and EMSA experiments.

\begin{tabular}{|c|c|c|}
\hline Purpose & Designation & Sequence $\left(5^{\prime} \rightarrow 3^{\prime}\right)$ \\
\hline \multirow[t]{2}{*}{ 5' RACE } & GSP1-A & ATCTGTGACATCTCCAGGGCATC \\
\hline & GSP2-A & GAAACTCTTCCGTCCTGAGTTTA CCATGGGC \\
\hline \multicolumn{3}{|c|}{ PCR of the promoter } \\
\hline \multirow[t]{6}{*}{ fragments } & Kpn-prom-S100P-S (-236) & TCCGGTACCTCAGTGATGGCGCCGAGACA \\
\hline & $B g l$-prom-S100P-A (-14) & GAAGATCTGGTGCTTTATAAGGCAGCCTA \\
\hline & $B g l$-prom-S100P-A2 (+58) & GAAGATCTGGTGCTAGATTCAGACCCAC \\
\hline & Kpn-prom-S100P-S (-1234) & TCCGGTACCTCTGAGTACCTCCGCTATAG \\
\hline & Xho-prom-S100P-A2 (+58) & TCCGCTCGAGGTGCTAGATTCAGACCCACC \\
\hline & del-prom-S100P-S (-124) & TGCATTTCATCAGAACTGAGCAC \\
\hline \multirow[t]{4}{*}{ RT PCR } & S100P-S & AAGGGGGAGCTCAAGGTGCTGA \\
\hline & S100P-A & ATCTGTGACATC TCCAGGGCATC \\
\hline & h- $\beta$-actin-S & CCAACCGCGAGAAGATGACC \\
\hline & $h-\beta$-actin-A & AGGATCTTCATGAGGTAGTCAGTC \\
\hline \multirow[t]{9}{*}{ EMSA } & prom-SMAD & GATGGCGCCGAGACACAGGT \\
\hline & cons1-SMAD & GGAGGTATGCAGACAACGAGTCAG \\
\hline & cons2-SMAD & AGCCAGACA \\
\hline & prom-STAT/CREB & GGGAAAGGTTCCAGAAACGTCAT \\
\hline & cons-STAT1 & ATTCCTGTAAG \\
\hline & cons-STAT4 & TTTCCCCCGAAA \\
\hline & cons-CREB & GATTGCCTGACGTCAGACAGC \\
\hline & prom-SP/KLF & 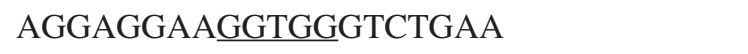 \\
\hline & cons-SP/KLF & GGGGGTGGG \\
\hline Inverse & del-SMAD-A & CCATCACTGAGGTACCTATCG \\
\hline \multirow[t]{5}{*}{ PCR } & del-SMAD-S & ACAGGTGAACACTGTAAAATGTGGATGC \\
\hline & del-STAT/CREB-A & CCCCAGCCAAGGCCCAGG \\
\hline & del-STAT/CREB-S & ATCACAACGATCCATTTCATCAG \\
\hline & del-SP/KLF-A & TTCCTCCTGGGGGCTGGC \\
\hline & del-SP/KLF-S & GTCTGAATCTAGCACCAGATC \\
\hline
\end{tabular}

Sequence motifs written in italic indicate restriction enzyme sites used for cloning of the amplified fragments, core sequences of the proposed transcription factor binding sites are underlined.

with Mo-MuLV reverse transcriptase (Finnzymes, OY, Finland) of RNA isolated from HeLa cells as described before (16). PCR consisted of initial denaturation step ( 2 min at $\left.94^{\circ} \mathrm{C}\right), 35$ amplification cycles $\left(45 \mathrm{sec}\right.$ at $94^{\circ} \mathrm{C}, 40 \mathrm{sec}$ at $60^{\circ} \mathrm{C}$ and $40 \mathrm{sec}$ at $72^{\circ} \mathrm{C}$ ) and the final extension $(7 \mathrm{~min}$ at $72^{\circ} \mathrm{C}$ ). The $5^{\prime}$ end of the RACE product was determined by sequencing.

Bioinformatic analysis. Potential cis-elements in S100P promoter were identified using different software including MatInspector (www.genomatics.de), Promoter Scan (bimas. dcrt.nih.gov/molbio/proscan), Promoter 2.0 (www.cbs.dtu. $\mathrm{dk} /$ services/promoter) and SoftBerry (www.softberry.com).

Construction of promoter reporter plasmids. Promoter fragments spanning the $-236 /-14,-236 /+58$ and $-1234 /+58$ regions were amplified by PCR from HeLa genomic DNA using the primers listed in Table I. Amplified fragments were digested with $\mathrm{KpnI}$ and $\mathrm{BglII}$ or $\mathrm{XhoI}$ and cloned into pGL3Basic vector (Promega) upstream of the luciferase reporter gene. Deletion constructs were amplified by inverse PCR on the $-236 /+58$ reporter plasmid using the listed primers (Table I) with the Phusion HF polymerase (Finnzymes) under the following conditions: denaturation for $5 \mathrm{~min}$ at $98^{\circ} \mathrm{C}, 35$ cycles for $40 \mathrm{sec}$ at $98^{\circ} \mathrm{C}, 40 \mathrm{sec}$ at $58^{\circ} \mathrm{C}, 80 \mathrm{sec}$ at $72^{\circ} \mathrm{C}$ and final elongation for $5 \mathrm{~min}$ at $72^{\circ} \mathrm{C}$.

Transient transfection and reporter gene assays. The cells were plated into 30-mm Petri dishes to reach approximately $60 \%$ monolayer density the next day. Transfection was performed with $2 \mu \mathrm{g}$ of the fragment-pGL3 plasmid and 100 ng of pRL-TK renilla vector (Promega) using GenePorterII reagent (Genlantis, San Diego, CA) according to manufacturer's recommendations. Reporter gene expression was 
assessed $48 \mathrm{~h}$ after transfection using a Dual-Luciferase Reporter Assay system (Promega). For the mitogenic or hormonal stimulation or inhibition, transfected cells were trypsinized and plated into 24 -well plates, allowed to attach for $20 \mathrm{~h}$, starved in serum-free medium for $24 \mathrm{~h}$ and treated in triplicates by different compounds [EGF $(1 \mathrm{nM})$, hydrocortisone $(1 \mu \mathrm{M})$, mithramycin A $(250 \mathrm{nM}), \operatorname{PD} 98059(50 \mu \mathrm{M})$, LY294002 (50 $\mu \mathrm{M})$, all from Sigma, St. Louis, MA] for additional $24 \mathrm{~h}$.

Preparation of nuclear extracts and electromobility shift assay (EMSA). Nuclear extracts were prepared from HeLa cells grown to a confluent monolayer in a $10-\mathrm{cm}$ dish. The cells were washed twice with ice-cold PBS, scraped, resuspended in $1 \mathrm{ml}$ of buffer A (10 mM HEPES pH 7.9, and $1.5 \mathrm{mM} \mathrm{MgCl}_{2}$ ) and kept on ice for $15 \mathrm{~min}$. The nuclei were pelleted by centrifugation for $5 \mathrm{~min}$ at $4,000 \mathrm{~g}$ at $4^{\circ} \mathrm{C}$ and resuspended in $200 \mu \mathrm{l}$ of buffer B (30 mM HEPES pH 7.9, $1.5 \mathrm{mM} \mathrm{MgCl}_{2}, 2 \mathrm{mM}$ DTT, $1 \mathrm{mM}$ PMSF, $10 \mu \mathrm{g} / \mathrm{ml}$ aprotinin and leupeptin, $500 \mathrm{mM} \mathrm{KCl}, 10 \%$ glycerol) and kept on ice for $15 \mathrm{~min}$. The extract was cleared by centrifugation for $5 \mathrm{~min}$ at $15,000 \mathrm{~g}$ at $4^{\circ} \mathrm{C}$ and the supernatant was stored in aliquots at $-80^{\circ} \mathrm{C}$ until use.

EMSA was performed by mixing $5 \mu \mathrm{g}$ of the nuclear extract with $40 \mathrm{fmol}$ of oligonucleotides (Table I), endlabeled with $\left[\gamma_{-}{ }^{32} \mathrm{P}\right]-\mathrm{ATP}$ using T4-polynucleotid kinase, in the binding buffer (10 mM Tris- $\mathrm{HCl} \mathrm{pH} 7.5,50 \mathrm{mM} \mathrm{NaCl}$, $1 \mathrm{mM}$ EDTA, $1 \mathrm{mM}$ DTT, 5\% glycerol, $2 \mu \mathrm{g}$ polydI-dC) for $25 \mathrm{~min}$ at room temperature. One-hundred molar excess of the unlabelled oligonucleotides was added to the reaction in the case of competitive assay. DNA-protein complexes were separated on the $5 \%$ native gel in the presence of $1 \mathrm{x}$ Trisglycine buffer (25 mM Tris- $\mathrm{HCl} \mathrm{pH} 8.0,190 \mathrm{mM}$ glycine, 1 mM EDTA).

\section{Results}

Identification of the core promoter of S100P gene. As the first step towards characterization of S100P promoter, we decided to localize the transcription initiation site, because the information from three different entries in Genebank database (namely NM_005980, BC006819, X65614) was inconsistent. We therefore performed an amplification of the 5' S100P cDNA ends (RACE). Sequence analysis of the 5' RACE product revealed a major transcription initiation site corresponding to a guanosine nucleotide localized $58 \mathrm{nt}$ upstream of the first ATG codon. This position was in full agreement with the transcription start site predicted by the SoftBerry Fprom promoter prediction program.

In order to identify the core promoter, we amplified a series of genomic fragments from the 5'-flanking region of S100P gene using the gene-specific primers listed in Table I and a genomic DNA isolated from HeLa cells as a template. The fragments were inserted into the pGL3-Basic reporter vector upstream of the firefly luciferase gene. Functional analysis of the resulting promoter constructs was done by transient transfections of cervical carcinoma HeLa cells that naturally express S100P mRNA (16) and thus apparently contain all relevant components of the transcriptional machinery needed for S100P gene transactivation.

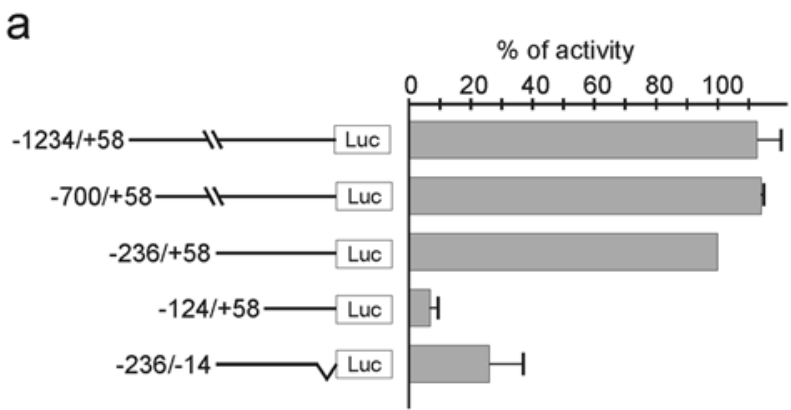

b

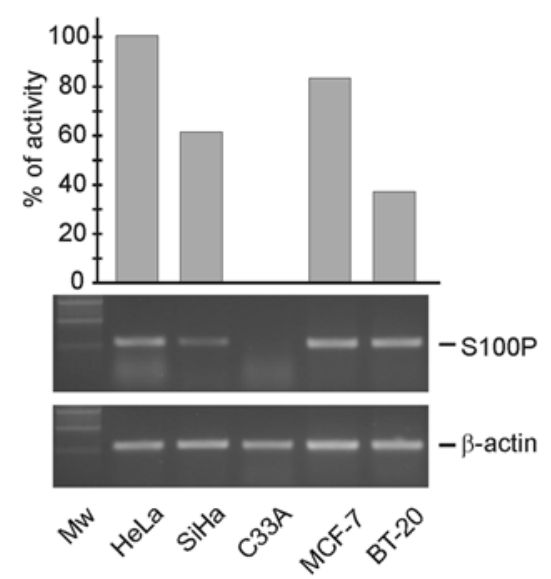

Figure 1. Basic promoter analysis and expression of S100P gene. (a) Transcriptional activities of the luciferase constructs containing truncated S100P promoter fragments. The numbers on the left indicate the position of terminal nucleotides of each genomic fragment with respect to transcription initiation site. Luciferase activities normalized to renilla are expressed in per cent relative to the core promoter construct $(-236 /+58)$ which was set to $100 \%$, bars represent mean values with standard deviations. Each transfection experiment was repeated 3-5 times and examined in triplicates to yield reproducible data. (b) Luciferase activities of the core promoter in different cancer cell lines were assessed as described above. RT PCR analysis of $\mathrm{S} 100 \mathrm{P}$ expression in the same cell lines is shown below the graph, C33A cell line was used as a negative control. PCR conditions were as follows: $95^{\circ} \mathrm{C}$ for $3 \mathrm{~min}, 30 \mathrm{cycles}$ of $95^{\circ} \mathrm{C}$ for $30 \mathrm{sec}, 60^{\circ} \mathrm{C}$ for $30 \mathrm{sec}, 72^{\circ} \mathrm{C}$ for $40 \mathrm{sec}$, and final extension $72^{\circ} \mathrm{C}$ for $5 \mathrm{~min}$. B-actin was used as an internal standard.

The luciferase activity produced by different promoter constructs showed that the core promoter of S100P gene is located within the $-236 /+58$ region (Fig. 1a). This region exhibited similar activity values as the larger $-700 /+58$ and $1234 /+58$ constructs. Interestingly, removal of the terminal sequences from either side of this region resulted in significantly reduced activity, corresponding to less than $10 \%$ in the absence of $-236 /-125$ fragment and to about $20 \%$ in the absence of $-13 /+58$ region. This finding suggests that the terminal sequences of the core promoter contain critical regulatory elements whose cooperation is required for full transcriptional activation of the S100P gene.

Activity of the core promoter was also assessed in three additional human cancer cell lines, including SiHa cervical carcinoma cells, and MCF-7 and BT-20 breast carcinoma cells. Luciferase values measured in these cell lines were expressed as per cent of the activity obtained in HeLa cells (Fig. 1b). The core promoter displayed the highest activity in HeLa cells, slightly decreased activity in MCF-7, and SiHa cells and was considerably less active in BT-20 cells. RT PCR analysis of S100P gene expression showed that all these cell 
a

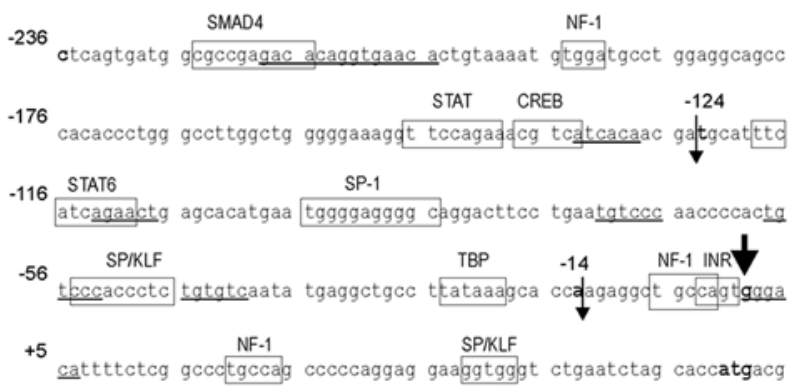

b

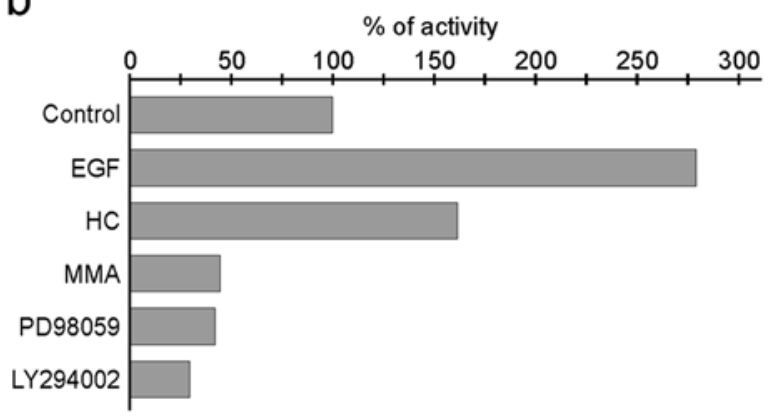

Figure 2. Sequence of the S100P core promoter and effects of different compounds on its activity in HeLa cells. (a) Nucleotide sequence of the -236/ +58 region with potential binding sites for transcription factors enclosed in the boxes. Thick arrow indicates position of the transcription start site determined by RACE, thin arrows show the ends of terminal truncations. Underlined sequences correspond to GRE motifs. (b) Transcriptional activity of the S100P core promoter in response to epidermal growth factor (EGF), hydrocortisone (HC), mithramycin A (MMA) and inhibitors of signal transduction PD98058 and LY294002. Luciferase activities normalized to renilla are expressed in per cent relative to the activity measured in untreated HeLa cells (control) that was set to $100 \%$.

lines exhibit the endogenous S100P transcript. On this basis, further promoter experiments were done in HeLa cells that naturally express S100P gene and show the best transcriptional activation.

Prediction of potential cis-regulatory elements. Computer analysis of the core promoter sequence with different software predicted several cis-acting elements potentially contributing to regulation of S100P gene transcription. Fig. 2a shows selected promoter elements of the highest predictive significance. For example, Inr initiator binding site was predicted at position -1/-4 just in front of the transcription initiation site (TIS) and TATA box was found at $-20 /-25$ position within the expected distance from TIS, supporting the view that the localization of TIS by 5' RACE was correct. In addition, the region upstream of TATA box was proposed to contain the binding sites for SMAD, overlapping STAT/CREB and SP-1 transcription factors, as well as several scattered GREs (glucocorticoid response elements). On the other hand, the sequence downstream of TIS was predicted to bind NF-1 and SP/KLF (Krüppel-like) transcription factors.

Some of the transcription factors potentially binding to S100P promoter are known to respond to signal transduction pathways activated by mitogenic or hormonal stimulation (22-24). These pathways involve signal transmission through a

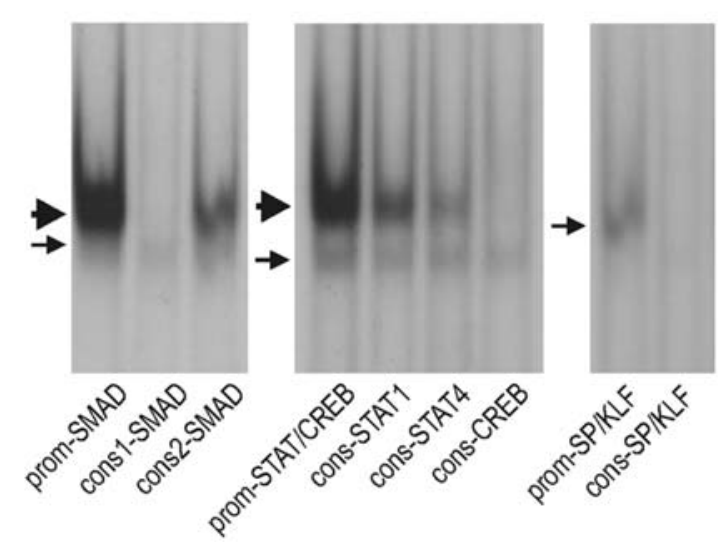

Figure 3. Electromobility shift assay of the putative binding sites for SMAD, STAT/CREB and SP/KLF transcription factors. EMSA was performed with the nuclear extracts from HeLa cells using the oligonucleotides derived from the predicted transcription factor-binding regions of the promoter. (a-c) DNA-protein complexes formed at putative SMAD-binding region a), STAT/ CREB-binding region (b) and SP/KLF-binding region (c) in the absence and presence of the competitor oligonucleotides are depicted by arrows.

MAPK or PI3K (phosphatidyl inositol 3-kinase) and thus can be blocked by specific inhibitors. Therefore, we analyzed the S100P promoter activity in HeLa cells transiently cotransfected with the core promoter luciferase construct and renilla plasmid. As expected, S100P activity was induced $>2$-fold by epidermal growth factor and 1.5 -fold by hydrocortisone, whereas mithramycin A, PD98059 and LY294002, inhibitors of SP-1, MAPK and PI3K, respectively, reduced the promoter activity to less than a half (Fig. 2b). These data indicated that the modulation of S100P promoter activity is consistent with the predicted set of the promoter elements and that at least some of them can transmit the signaling to transcriptional regulation of the S100P gene.

Electromobility shift assay of the predicted binding sites. As shown above, both terminal regions of the core promoter were required for the full promoter activation and their removal led to significant decrease of the luciferase values. The 5' region (-236/-125) was predicted to contain SMAD4 and STAT/CREB binding sites, and the 3' region (-13/+58) appeared to include a recognition element for SP/KLF transcription factors. In order to see, whether these binding sites are occupied by nuclear proteins, we carried out an electromobility shift assay (EMSA) using oligonucleotides derived from corresponding promoter fragments alone or in competition with excess of consensus binding motifs (Table I).

First we used an oligonucleotide corresponding to -230/ -211 region that was proposed to contain the binding site for SMAD transcription factor (Prom-SMAD), which produced one dominant band and one less shifted weak band (Fig. 3a). The dominant band was completely lost in competitive assay with non-labeled 24-nt SMAD-binding consensus (cons1SMAD), whereas only part of it was competed by a shorter 9-nt consensus probe (cons2-SMAD) supporting the view that the promoter fragment can bind a SMAD-related transcription factor and that the flanking sequences contribute to this interaction. In the second analysis, we used a probe 


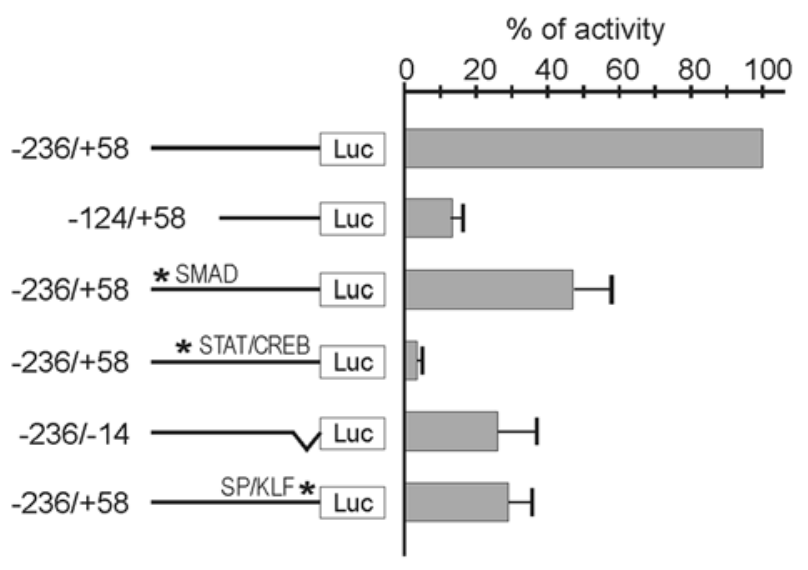

Figure 4. Transcriptional activities of S100P promoter constructs with internal deletions in putative regulatory elements. Reporter constructs with internal deletions were produced by inverse PCR and transfected to HeLa cells. Luciferase activities normalized to renilla are expressed in per cent relative to the core promoter construct $(-236 /+58)$ which was set to $100 \%$, bars represent mean values with standard deviations. Each transfection experiment was repeated 3-5 times and examined in triplicates to yield reproducible data.

corresponding to $-155 /-133$ region presumably containing the overlapping binding sites for STAT and CREB transcription factors. The EMSA profile showed one weak band that was independent of the addition of non-labeled competitor oligonucleotides and one very strong band, which was partially competed by two 11-nt and 12-nt consensus motifs corresponding to STAT1 and STAT4 binding sites, respectively (Fig. 3b). A complete loss of this strong band was observed with a non-labeled CREB consensus probe suggesting either preferential/stronger binding of CREB over STAT to this promoter region or reflecting a bigger longer size of the CREB-related competitor. The third oligonucleotide represented the $+30 /+49$ region located downstream of the transcription initiation site within the leader sequence. This probe, predicted to contain CACC-element for SP/KLF transcription factors, produced only a weak single band that was entirely competed by a non-labeled 12-nt consensus motif indicating that also this region has the capacity to bind a transcription factor (Fig. 3c).

Functional analysis of cis-regulatory elements using deletion constructs. In order to demonstrate a functional relevance of the regulatory elements located within the analyzed core promoter regions, we produced promoter constructs with internal deletions of the binding sites for SMAD, overlapping STAT/CREB, and for SP/KLF transcription factors. These were generated by inverse PCR using the primers related to sequences flanking the intended deletion (Table I) and the $-236 /+58$ promoter construct as a template. All deletion constructs were transiently transfected to HeLa cells as described above and luciferase activities were measured $48 \mathrm{~h}$ later. As shown on Fig. 4, the lowest activity $(<5 \%$ of the intact promoter activity) was obtained with the STAT/CREB deletion construct $(-153 /-137)$ suggesting that this region is the most critical for activation of S100P transcription. Less prominent reduction (46\%) was obtained with the SMAD deletion construct (-225/-217). Analysis of an additional construct with the deletion of SP/KLF element $(+38 /+42)$, revealed that the promoter activity decreased to about $25 \%$ of the intact core promoter. Comparable activity value was obtained in HeLa cells in the absence of the entire $-13 /+58$ region (Fig. 4). Taking these data together, we can propose that the $\mathrm{S} 100 \mathrm{P}$ promoter activation is principally mediated by three regulatory elements: STAT/CREB-binding region, SMAD-binding site and SP/KLF element.

\section{Discussion}

Expression of the S100P gene, originally identified in placenta, has been associated with cancer in a number of immunohistochemical and microarray studies of human tissues. These consistently showed that S100P transcription correlates with various features of malignant phenotype including hormone independence and resistance to chemotherapy $(9-15,17)$. Two independent studies also demonstrated that ectopic expression of S100P was accompanied by acquisition of tumorigenic potential in vivo $(16,17)$. In spite of this consistent link to cancer, regulation of S100P expression has remained unexplored, although some clues could be deduced from data showing the role of hormones and growth factors that influence the level of S100P in certain types of tissues.

Herein we provide the first information relevant for understanding the S100P gene regulation in cancer cells. We determined the position of transcription initiation site and identified the genomic region that encompasses the core promoter. We also identified cis-regulatory elements that play a critical role in transcriptional activation of S100P gene and bind nuclear proteins. Our data clearly suggest the functional implication of the STAT/CREB, SMAD and $\mathrm{SP} / \mathrm{KLF}$ binding sites in the control of S100P expression.

Involvement of these regulatory elements is quite compatible with the cancer-related expression pattern of S100P gene, because the signal transduction pathways that converge on these types of transcription factors are frequently activated in different tumors (22-27).

The STAT proteins mediate transcriptional responses to many cytokines and growth factors (including EGF). These stimuli induce the formation of dimers composed of different combinations of six isoforms. STATs, particularly the isoforms 1,3 and 5, operate in a wide variety of tumors where they upregulate genes involved in control of cell proliferation and survival and thereby contribute to tumor progression (22).

The cAMP response element-binding protein CREB responds to various stimuli such as growth factors and stress signals that elevate intracellular cAMP or $\mathrm{Ca}^{2+}$ levels. CREB supports proliferation, survival and malignant transformation via transcriptional regulation of several thousand genes including proto-oncogenes, cytokines and cell cycle components, and is frequently constitutively active in tumor cells (23).

SMAD proteins, existing in eight isoforms, are intracellular transducers of TGF- $\beta$ signaling and their malfunctions are implicated in cancer and other serious human diseases (24). SMADs seem to be unable to directly recruit the basal transcriptional machinery to responsive promoters and instead regulate transcription through chromatin remodeling (25). This fact could explain why deletion of SMAD-binding motif 
did not have such a dramatic effect on the activity of S100P promoter when compared to deletion of STAT/CREB region. SMADs can also cooperate with other transcription factors including AP-1, CREB/ATF3 and SP-1 (26). Binding sites for these transcription factors are present also in the core promoter and thus it is quite conceivable that such cooperation could occur also in the context of $\mathrm{S} 100 \mathrm{P}$ regulation.

SP/KLF family contains at least 20 members (including SP-1) that have different transcriptional properties. They are involved in many growth-related signal transduction pathways, interact with oncoproteins and tumor suppressors, and can be oncogenic (27). Furthermore, these types of transcription factors can modulate each other's activities and cross-talk with glucocorticoid receptors $(28,29)$. Indeed, GREs (not investigated in detail in this study) can also play a role in regulation of S100P gene because the core promoter contains several GRE motifs (some of them overlap with the herein identified key elements) and responds to hydrocortisone.

Due to complex relationships among these transcription factors, better understanding of the molecular anatomy of $\mathrm{S} 100 \mathrm{P}$ promoter and related upstream pathways will require identification of STAT, SMAD and SP/KLF isoforms participating in regulation of $\mathrm{S} 100 \mathrm{P}$ gene expression, because various isoforms differ by target selectivity and specific roles in responses to various stimuli. This study provides a solid basis enabling the achievement of this goal.

\section{Acknowledgements}

This study was supported by the Slovak Scientific Grant Agency (VEGA 2/5082/5) and by Sigrid Juselius Foundation, Academy of Finland, the Medical Research Fund of Tampere University Hospital.

\section{References}

1. Marenholz I, Heizmann CW and Fritz G: S100 proteins in mouse and man: from evolution to function and pathology. Biochem Biophys Res Commun 322: 1111-1122, 2004.

2. Emoto Y, Kobayashi R, Akatsuba H and Hidaka H: Purification and characterization of a new member of the $\mathrm{S} 100$ protein family from human placenta. Biochem Biophys Res Commun 182: 1246-1253, 1992.

3. Becker T, Gerke V, Kube E and Weber K: S100P, a novel $\mathrm{Ca}(2+)$-binding protein from human placenta. cDNA cloning, recombinant protein expression and $\mathrm{Ca}^{2+}$ binding properties. Eur J Biochem 207: 541-547, 1992.

4. Gribenko A, Lopez MM, Richardson MM III and Makhatadze GI: Cloning, overexpression, purification and spectroscopic characterization of human S100P. Protein Sci 7: 211-215, 1998.

5. Zhang H, Wang G, Ding Y, Wang Z, Barraclough R, Rudland PS, Fernig DG and Rao Z: The crystal structure at $2 \mathrm{~A}$ resolution of the $\mathrm{Ca}^{2+}$-binding protein S100P. J Mol Biol 325: 785-794, 2003.

6. Koltzscher M, Neumann C, Konig S and Gerke V: $\mathrm{Ca}^{2+}$ dependent binding and activation of dormant ezrin by dimeric S100P. Mol Biol Cell 14: 2372-2384, 2003.

7. Filipek A, Jastrzebska B, Nowotny M and Kuznicki J: CacyBP/ SIP, a calcyclin and Siah-interacting protein, binds EF-hand proteins of the S100 family. J Biol Chem 277: 28848-28852, 2002.

8. Arumugam T, Simeone DM, Schmidt AM and Logsdon CD: S100P stimulates cell proliferation and survival via receptor for activated glycation end products (RAGE). J Biol Chem 279: 5059-5065, 2004.

9. Guerreiro Da Silva ID, Hu YF, Russo IH, Ao X, Salicioni AM, Yang X and Russo J: S100P calcium-binding protein overexpression is associated with immortalization of human breast epithelial cells in vitro and early stages of breast cancer development in vivo. Int J Oncol 16: 231-240, 2000.
10. Mackay A, Jones C, Dexter T, Silva RL, Bulmer K, Jones A, Simpson P, Harris RA, Jat PS, Neville AM, Reis LF, Lakhani SR and O'Hare MJ: cDNA microarray analysis of genes associated with ERBB2 (HER2/neu) overexpression in human mammary luminal epithelial cells. Oncogene 22: 2680-2688, 2003.

11. Schor AP, Carvalho FM, Kemp C, Silva ID and Russo J: S100P calcium-binding protein expression is associated with high-risk proliferative lesions of the breast. Oncol Rep 15: 3-6, 2006.

12. Logsdon CD, Simeone DM, Binkley C, Arumugam T, Greenson JK, Giordano TJ, Misek DE, Kuick R and Hanash S: Molecular profiling of pancreatic adenocarcinoma and chronic pancreatitis identifies multiple genes differentially regulated in pancreatic cancer. Cancer Res 63: 2649-2657, 2003.

13. Crnogorac-Jurcevic T, Missiaglia E, Blaveri E, Gangesaran R, Jones M, Terris B, Costello E, Neoptolemos JP and Lemoine NR: Molecular alterations in pancreatic carcinoma: expression profiling shows that dysregulated expression of S100 genes is highly prevalent. J Pathol 201: 63-74, 2003.

14. Amler LC, Agus DB, Le Duc C, Sapinoso ML, Fox WD, Kern S, Lee D, Wang V, Leyssens M, Higgins B, Martin J, Gerald W, Dracopoli N, Cordon-Cardo C, Scher HI and Hampton GM: Dysregulated expression of androgen-responsive and nonresponsive genes in the androgen-independent prostate cancer xenograft model CWR22-R1. Cancer Res 60: 6134-6141, 2000.

15. Mousses S, Bubendorf L, Wagner U, Hostetter G, Kononen J, Cornelison R, Goldberger N, Elkahloun AG, Willi N, Koivisto P, Ferhle W, Raffeld M, Sauter G and Kallioniemi OP: Clinical validation of candidate genes associated with prostate cancer progression in the CWR22 model system using tissue microarrays. Cancer Res 62: 1256-1260, 2002.

16. Gibadulinova A, Barathova M, Kopacek J, Hulikova A, Pastorekova S, Kettmann R and Pastorek J: Expression of S100P protein correlates with and contributes to the tumorigenic capacity of HeLa cervical carcinoma cells. Oncol Rep 14: 575-582, 2005.

17. Wang G, Platt-Higgins A, Carroll J, De Silva Rudland S, Winstanley J, Barraclough R and Rudland PS: Induction of metastasis by $\mathrm{S} 100 \mathrm{P}$ in a rat mammary model and its association with poor survival of breast cancer patients. Cancer Res 66: 1199-1207, 2006.

18. Averboukh L, Liang P, Kantoff PW and Pardee AB: Regulation of S100P expression by androgen. Prostate 29: 350-355, 1996.

19. Sato N, Fukushima N, Matsubayashi H and Goggins M: Identification of maspin and $\mathrm{S} 100 \mathrm{P}$ as novel hypomethylation targets in pancreatic cancer using global gene expression profiling. Oncogene 3: 1531-1538, 2004.

20. Wang Q, Williamson M, Bott S, Brookman-Amissah N, Freeman A, Nariculam J, Hubank MJ, Ahmed A and Masters JR: Hypomethylation of WNT5A, CRIP1 and S100P in prostate cancer. Oncogene 26: 6560-6565, 2007.

21. Shyu RY, Huang SL and Jiang SY: Retinoic acid increases expression of the calcium-binding protein $\mathrm{S} 100 \mathrm{P}$ in human gastric cancer cells. J Biomed Sci 10: 313-319, 2003.

22. Quesnelle KM, Boehm AL and Grandis JR: STAT-mediated EGFR signaling in Cancer. J Cell Biochem 102: 311-319, 2007.

23. Siu YT and Jin DY: CREB - a real culprit in oncogenesis. FEBS J 274: 3224-3232, 2007.

24. Schmierer B and Hill CS: TGF-SMAD signal transduction: molecular specificity and functional flexibility. Nat Rev Mol Cell Biol 8: 970-982, 2007.

25. Ross S, Cheung E, Petrakis TG, Howell M, Krauss WL and Hill CS: SMADs orchestrate specific histone modifications and chromatin remodeling to activate transcription. EMBO J 25: 4490-4502, 2006.

26. Massagué J, Seoane J and Wotton D: Smad transcription factors. Genes Dev 19: 2783-2810, 2005.

27. Black AR, Black JD and Azizkhan-Clifford J: Sp1 and Krüppellike factor family of transcription factors in cell growth regulation and cancer. J Cell Physiol 188: 143-160, 2001.

28. Kassel O and Herrlich P: Crosstalk between the glucocorticoid receptor and other transcription factors: molecular aspects. Mol Cell Endocrinol 275: 13-29, 2007.

29. Schoneveld OJLM, Gaemers IC and Lamers WH: Mechanisms of glucocorticoid signaling. Biochim Biophys Acta 1680: 114-128, 2004. 